\title{
Pens

\section{MUJERES POETAS QUE DESHACEN LAS NORMAS DE GÉNERO: DEL CANIBALISMO ERÓTICO AL PORNOTERRORISMO EN LA ESPAÑA DEL SIGLO XXI}

\author{
WOMEN POETS WHO DISMANTLE GENDER NORMS: \\ FROM EROTIC CANNIBALISM TO PORNOTERRORISM \\ IN THE SPAIN OF THE 21ST CENTURY \\ Claire Laguian \\ Université de Paris-Est Marne-la-Vallée \\ clairelaguian@yahoo.fr
}

Resumen: En esta contribución, se estudian los ataques de la poesía lesbiana y queer española del siglo XxI a las convenciones poéticas y de género, dentro de las esferas de la escritura pornográfica en una veintena de poemarios recientes. Con perspectivas de Queer y Gender studies, se analizan las modalidades poéticas de rehabilitación de las voces lesbianas eróticas en genealogías literarias ocultadas por las normas heteropatriarcales. La omnipresencia de los deseos vampíricos, caníbales y la reescritura del "cuerpo lesbiano" en voz propia permiten desembocar sobre el análisis de las subversiones poéticas BDSM que llevan a cabo las poetas. También se remite en este artículo a la expresión poética de sexualidades transgresoras heredadas de los movimientos posporno, queer y pornoterrorista, este último concepto siendo creado por la activista Diana J. Torres.

PALABRAS CLAVE: poesía; pornografía; sexualidades lesbianas y queer; canibalismo; BDSM; pornoterrorismo

ABSTRACT: This article focuses on the foray of Spanish lesbian and queer poetry of the 21st century against the poetic and gender conventions, in more than twenty recent collections of pornographic poems. Using the framework of Queer and Gender studies, we examine the poetic modalities of rehabilitation of erotic and lesbian voices, which were occulted by heteropatriarchal norms. The omnipresence of vampiric and cannibal desires and the rewriting of the lesbian body's own voice lead to an analysis of poetic BDSM subversions performed by the poets. This article also delves into poetic expression of transgressive sexualities 
inherited from postporn, queer and pornoterrorist movements, the latter being a concept created by activist Diana J. Torres.

Keywords: Poetry; Pornography; Lesbian and Queer Sexualities; Cannibalism; BDSM; Pornoterrorism

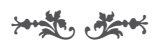

La poesía, género asociado a lo refinado, lo noble y académico, casi nunca se cita dentro de los Porn studies: en efecto, a lo carnal en los versos, se le suele aplicar más bien el adjetivo "erótico", o el término sentimentalista "amoroso", y no la crudeza pornográfica. Es más, lo lírico correspondería intrínsecamente a lo sublime, cuando lo blasfematorio y lo ob-sceno ${ }^{1}$ quedarían fuera de las normas estéticas del género poético. Como prueba de ello, Marie-Anne Paveau, en su libro Le discours pornographique, retoma las reflexiones de Dominique Maingueneau al explicar que "le texte pornographique, doté d'une écriture référentielle, c'est-à-dire formulant directement les réalités du monde, [s'oppose] à la poésie par exemple, qui est elle axée sur les jeux du signifiant" (Paveau 2014: 195). Pero si el cine y la fotografía, la narrativa y el teatro pueden expresar lo pornográfico al pasar por la ficcionalización, al manipular diversos tipos de técnicas creativas, y al apoyarse sobre juegos de significantes específicos, ¿por qué no la poesía?

En el presente artículo, abordaremos el estudio de poemas escritos a partir del 2000, en castellano y catalán, por artistas mujeres que poetizan cuerpos de mujeres que desean a otras mujeres, o deseos fuera de cualquier binarismo. Cabe señalar que esta escritura de deseos y sexualidades no normativos se realiza sin juegos de géneros entre los pronombres, al contrario de lo que tenían que hacer antaño las escritoras para ocultar las representaciones de relaciones sáficas mediante el uso enmascarado del pronombre masculino. Estudiaremos entonces la puesta en lenguaje de la crudeza de esta escritura o "grafía porno", que se fragua un camino editorial mediante la poesía lesbiana, queer y transfeminista ${ }^{2}$ en la España del siglo xxı, poesía que politiza y subjetiviza las sexualidades marginadas. Al enfocar nuestro propósito en una veintena de creaciones

\footnotetext{
1 Con el concepto de 'obscenidad', nos referimos a la definición que da Marie-Anne Paveau de este término: "on la définit comme une offense à la pudeur en matière sexuelle ou au bon goût en matière sociale. [...] II s'agit donc d'une transgression des normes de l'acceptable dans le domaine moral, social ou esthétique" (2014: 37).

2 El transfeminismo, concepto ideado por varias activistas y pensadoras feministas de la esfera hispanohablante, aparece definido en el manifiesto recogido por Diana J. Torres como una subversión contra el feminismo hegemónico blanco, heterosexual y burgués que no pone en tela de juicio, entre otras cosas, el binarismo de género: "Ya no nos vale con ser solo mujeres. El sujeto político del feminismo 'mujeres' se nos ha quedado pequeño, es excluyente por sí mismo, se deja fuera a las bolleras, a Ixs trans, a las putas, a las del velo, a las que ganan poco y no van a la uni, a las que gritan, a las sin papeles, a las marikas..." (Torres 2011: 173). A propósito de esta corriente feminista, se puede consultar la obra colectiva editada por Miriam Solá y Elena Urko: Transfeminismos. Epistemes, fricciones y flujos, publicada en 2013 por Txalaparta.
} 
contemporáneas, queremos precisar que no haremos una diferencia clasista, moralista ni opresiva entre los conceptos de "erotismo" y de "pornografía", siguiendo de esta forma unas reflexiones de Marie-Anne Paveau:

Cette différence entre l'érotique et le pornographique est essentiellement argumentative: elle justifie des propos, représentations ou pratiques liées au sexe en évitant leur condamnation, permet de condamner la pornographie en sauvant la sexualité, et aide à la conservation des mythologies amoureuses et des arts de la séduction généralement hétérosexistes et peu ouverts à la curiosité et à l'invention en matière sexuelle. Ce que Gayle Rubin appelle très justement "l'oppression sexuelle". (Paveau 2014: 39)

Partiendo de estos presupuestos, intentaremos entender cómo algunas voces poéticas subvierten, en una primera persona del femenino y no heterocentrada, los códigos pornográficos hegemónicos, y cómo visibilizan los cuerpos y las sexualidades no convencionales, mediante escrituras que tienen como denominador común "devorar" las normas, o comprometerse políticamente.

En un primer momento, nos interesaremos por las diversas modalidades utilizadas por las poetas ${ }^{3}$ contra el monopolio masculino y heteronormativo de la pornografía, así como de las escrituras poéticas eróticas. A continuación, trataremos la reapropiación del "cuerpo lesbiano"4 por parte de estas voces poéticas, mediante una poetización dislocadora de las sexualidades vampírica, caníbal y BDSM. ${ }^{5}$ Para terminar, analizaremos las recientes propuestas poéticas inspiradas en los movimientos queer y posporno, ${ }^{6}$ a través de las creaciones transgresoras de los nuevos feminismos españoles, tales como el transfeminismo y el pornoterrorismo.

\section{Estratagemas de RECUPERACIÓN DEL ESPACIO LITERARIO Y PORNOGRÁFICO}

La Antología de la poesía erótica de nuestro tiempo, de 1973, y El jardí de les malícies: de la poesia eròtica universal, de 2001, contienen un $100 \%$ de poetas masculinos (a pesar del uso del adjetivo "universal"). Hay que esperar a la antología editada por la poeta Pura Salceda en 2010, Erato bajo la piel del deseo:

\footnotetext{
3 Precisamos que utilizaremos el término de "poeta", y no "poetisa", puesto que las artistas estudiadas en este texto no se presentan con el vocablo en femenino, sino con la forma supuestamente genérica de "poeta" (y carente de connotación peyorativa).

${ }^{4}$ Con esta expresión, aludimos a la obra de Monique Wittig de la que hablaremos más adelante.

${ }^{5}$ Bondage y Disciplina; Dominación y Sumisión; Sadismo y Masoquismo. No utilizaremos aquí la palabra "sadomasoquismo", al ser un estigma patologizante empleado por Freud, por la medicina y la psiquiatría responsables del DSM (manual diagnóstico y estadístico de los trastornos mentales).

6 Las definiciones de los conceptos tales como "pornografía", "postporno" o "prosexo" no se añadirán en este texto para no alargarlo demasiado. En efecto, ya aparecen en la introducción propuesta por las coordinadoras de este número, Marta Álvarez y Amélie Florenchie. Para tener detalles sobre el contexto de desarrollo del postporno en la esfera barcelonesa, véase el libro de Lucía Egaña publicado en 2017: Atrincheradas en la carne. Lecturas en torno a las prácticas postpornográficas.
} 
antología de poesía erótica, para descubrir a cuarenta y una escritoras sobre un total de noventa poetas. La sociedad suele asumir que el erotismo y la pornografía se hacen en su mayoría en masculino, y estas antologías poéticas parecen confirmarlo, aunque es cierto que las estadísticas son un mero indicador, no siempre suficiente ni categórico. A las mujeres, no se les concedía más que el papel de musa, cuyo cuerpo venía objetivado y dominado por una mirada y una escritura masculinas designadas como heterosexistas. Así lo señalaron Sheila Rowbotham: "nos conocemos a nosotras mismas a través de mujeres hechas por hombres" (1977: 40), y Virginie Despentes: "Les hommes seuls imaginent le porno, le mettent en scène, le regardent, en tirent profit et le désir féminin est soumis à la même distorsion: il doit passer par le regard masculin" (2006: 103). A las voces femeninas, se les reservaba "el sensualismo más sutil" (Salceda 2010: 14); sin embargo, las poetas de las que hablaremos más adelante deciden encarnar voces potentes y transgresoras a contracorriente de la silenciación sistémica.

Cabe notar que todas ellas reivindican a su manera un espacio doblemente ocultado en el canon poético: el de los deseos expresados por las mujeres, y el de los deseos expresados por las lesbianas. ${ }^{7}$ Es aleccionador pensar que el (casi) único modelo lésbico vital y poético conocido es Safo de Mitilene y sus pocos versos lacunarios que quedan tras su destrucción por la Iglesia Católica, como bien lo recuerda Carmen Moreno en la introducción a su antología poética de 2012, Mujeres que aman a mujeres (Moreno 2012: 7). En España, la primera poeta en escribir el deseo lésbico y reconocida por la historiografía es Lucía Sánchez Saornil que, como bien se sabe, solía firmar la mayoría de sus poemas con un seudónimo masculino. ${ }^{8}$ En efecto, la asunción de un yo femenino deseante y, aún más, lesbiano, era en sí imposible según las normas moralizadoras de la sociedad de principios del siglo xx y por la "decencia" impuesta a las mujeres. Las poetas actuales a las que estudiaremos aquí llevan a cabo entonces una triple desestabilización radical: introducen el deseo pornográfico en la poesía, lo hacen en femenino, y tratan la carnalidad lesbiana, o las diversas maneras de vivir sexualidades fuera de las normas binarias de género y orientaciones sexuales.

Para las poetas del $\mathbf{x x I}$, se trata pues de ocupar el terreno9 ${ }^{9}$, visibilizando en su escritura las genealogías ocultadas, y construyendo puentes lesbianos intertextuales con citas introductorias de poetas extranjeras. Por ejemplo, se convoca a la mismísima Safo en el poema de Laia López Manrique "Y hablarías de ello limpiamente" (2014: 54), cuyo título es justamente una cita de la poeta

\footnotetext{
7 Cuando las voces homoeróticas masculinas tuvieron un espacio propio (aunque silenciado a veces) en el panorama poético español del siglo xx, sin buscar más lejos: García Lorca, Aleixandre, Cernuda, etc.

8 Una forma también de performativizar la identidad, estudiada en profundidad por Elena Castro en su libro sobre las poetas lesbianas españolas de los siglos XX y XXI, Poesía lesbiana queer. Cuerpos y sujetos inadecuados (2014: 18-29).

9 Según lo que ya pedía la antropóloga lesbiana Gayle Rubin en 1986: "Il y a tout l'espace que l'on voudra pour améliorer le porno et pour créer des pornos bien faits, créatifs, plus diversifiés, plus en accord avec les fantasmes des femmes, et plus nourris de conscience féministe. Cela n'arrivera que si plus de femmes et de féministes s'engagent dans la production de produits représentant une sexualité explicite" (Rubin 2010: 310).
} 
de Mitilene. Se crea una red lesbiana internacional con palabras de las escritoras Renée Vivien, Djuna Barnes, Marguerite Yourcenar o Elizabeth Bishop, trazando así las huellas de lo que nos puede recordar lo que la poeta y ensayista Adrienne Rich llamaba la "existencia lesbiana". ${ }^{10}$ Por otro lado, los nombres de las poetas lesbianas de lenguas castellana y catalana, y que fueron precursoras en el siglo $x x$, surgen de manera recurrente en el espacio de la página, con citas eróticas. Por ejemplo, la figura de Gloria Fuertes se integra dentro de un poema de Txus García en una invocación suprema: "Pero te juro por Gloria Fuertes/ que hoy sí que me rebelo" (García 2011: 73). Por su parte, la gran poeta catalana Maria Mercè Marçal viene citada por Ana Martínez en Cartografía del deseo, y por Mireia Calafell en Poètiques del cos.

En cuanto a la poeta Concha García, ella firma el prólogo al poemario volveré mucho más tarde de las doce de María Castrejón (2011: 15-19). Del mismo modo, Cristina Peri Rossi, poeta uruguaya y española afincada definitivamente en la península desde 1974, escribe el prólogo al poemario Gran amor de Ma Ángeles Cabré (2011: 9-12), poeta que a su vez prologa el poemario L'esbós de Sílvia Bel (2010: 11-14). Esta última poeta catalana, en este mismo poemario que homenajea a Safo con su juego de palabras isleño, ${ }^{11}$ encabeza su poema "11-S" con un fragmento del poema erótico "Once de septiembre" de Cristina Peri Rossi. Y, así, se cierra el círculo... Con este poema "11-S", Sílvia Bel se inscribe claramente en la genealogía de Peri Rossi al utilizar el adverbio "també" en la expresión "jo també estaba fent l'amor" (Bel 2010: 57), en eco y respuesta paralelística a "El once de septiembre del dos mil uno/ mientras las Torres Gemelas caían / yo estaba haciendo el amor" (Peri Rossi 2014: 845). Con todos estos peritextos e intertextos, las poetas lesbianas del siglo xxI conquistan el espacio erótico robado durante siglos, y crean redes interconectadas para rehabilitar antiguas voces y visibilizar el deseo lesbiano en el canon poético.

La parodia y el desplazamiento incongruente de los escritos provenientes de una norma heteropatriarcal, y que suelen convertir la sexualidad lésbica en una sexualidad presentada como vainilla, ${ }^{12}$ permiten hacer de estas voces verdaderos sujetos pornográficos, y ya no objetos pasivos del deseo masculino. Es el caso de Diana J. Torres, en su libro Pornoterrorismo y en su blog, que nos propone versiones porno del poema "Hombre" de Blas de Otero (Torres 2009) y del "Poema n. ${ }^{0}$ 15" de Pablo Neruda (Torres 2011: 200). Por otra parte, Ana Tapia parece reapropiarse de La religieuse de Diderot con dos de sus poemas salvajes y caníbales (volveremos sobre esta desestabilización del deseo normativo más adelante) que ponen en escena la escandalosa relación sexual entre dos mujeres

\footnotetext{
10 "Existencia lesbiana sugiere tanto el hecho de la presencia histórica de las lesbianas como nuestra continua creación del significado de esa existencia" (Rich 1996: 13).

11 También nos regala una cremallera roja entre sus páginas, cerrada, y nos invita entonces a abrirla tanto como al libro.

12 Este término peyorativo, utilizado en los años 80 en los escritos de Gayle Rubin, se creó en las esferas BDSM para designar la sexualidad convencional, y presentada como aburrida, sin imaginación ni atrevimiento.
} 
de un convento, dedicando por cierto el primero de ellos a la monja Benedetta Carlini que fue condenada a la cárcel en el siglo XVı por sus amores lésbicos:

Y cómo es cuando ella te desnuda con la furia de un súcubo y te rasga las prendas y las tira después de cualquier forma, eh, cómo es, desgraciada, ese momento en que su lengua fiera te succiona un pezón, uno tan solo y tú lloras y suplicas que más rápido que ya no puedes aguantar y en el pasillo todas pueden oír tus gemidos de bestia asilvestrada, cómo es, confiesa, cuando esa vil mujer cierra sus negras fauces sobre tu pico enhiesto entre los muslos y tú dices ya está, ya me has matado. (Tapia 2012: 50)

Fíjate, sor, qué locas estamos:

caminamos desnudas por la orilla del río

mordemos la piel de los árboles

y luego nos reímos

nos metemos un pez entre las piernas

sor

pero solo el instante del gemido, y después

nos frotamos los senos con savia de almendro.

Como estamos tan locas ya da igual lo que hagamos.

Como ya hemos pecado es un deber disfrutarlo. [...]

Llegamos a la aldea y nos follamos a un macho

cabalgando sobre él una dos y a la de tres

y luego nos follamos también a su esposa. (Tapia 2012: 39)

La burla contra el porno mainstream aparece en el poema caricaturesco "Oh my God cómo me gustas" de Txus García, que nos recuerda el tratamiento inverosímil y exagerado de la sexualidad lésbica en este tipo de pornografía hecha por y para los hombres:

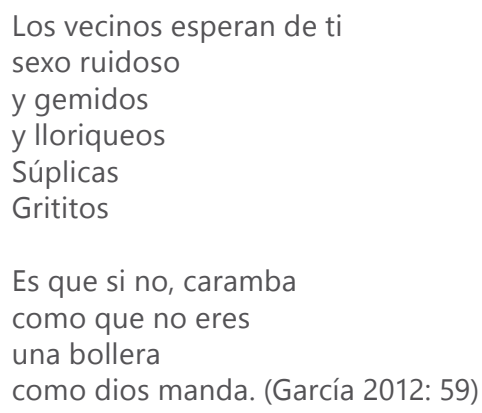

Por su parte, Cristina Peri Rossi y Sílvia Bel invitan también al género pornográfico de manera poco convencional, pero esta vez integrándolo a la situación más trágica de principios de siglo, los atentados del 11-S, como ya lo hemos avanzado anteriormente. En efecto, Sílvia Bel prolonga el poema de Peri Rossi de 2004: en su propio poema en catalán, aquella hace un paralelo entre su actividad sexual desenfrenada con una mujer y la caída de las Torres Gemelas en la 
pantalla de la televisión, comparándola con una película porno, y de esta forma desestabiliza los códigos del porno mainstream al confrontarlos irónicamente con este drama:

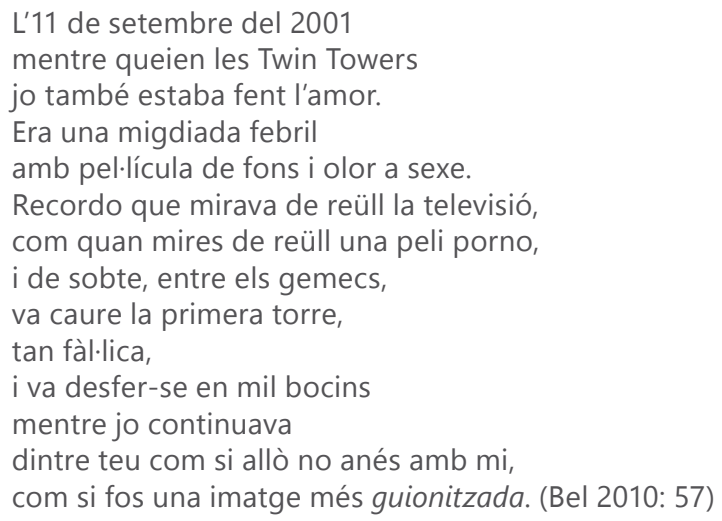

En cuanto a Cristina Peri Rossi, lleva con incongruencia el porno al ámbito muy académico de la biblioteca en su poema "Punto de encuentro": "Ese sexshop me recordaba también/ a una biblioteca, con sus anaqueles de separación/ y sus clasificados, aquí porno duro, aquí videos gay, aquí/ sadomaso, allá queers y travestís" (Peri Rossi 2009: 31). Así consigue desplazar las expectativas habituales, y orientar a los lectores hacia una mirada renovada e incluso literaria sobre el porno. El significante poético y sus sonidos cobran una perspectiva pornográfica en otro poema de Cristina Peri Rossi, cuando esta poeta relaciona su excitación sexual con las letras que su amante pronuncia por teléfono, letras que surgen también en este poema: "me como tus vocales/ devoro tus eses y tus eles/ me palpita el sexo con tu risa" (Peri Rossi 2005: 816).

Encarnar con voz propia la pornografía y reapropiarse el deseo lesbiano con genealogías poéticas subversivas, paródicas e incongruentes, es lo que estas poetas del siglo xxı se proponen, con un punto común deslumbrador que radica en su capacidad para escribir de manera mordiente las sexualidades marginadas, tal como ya se podía vislumbrar con el campo léxico presente en los dos poemas de Ana Tapia citados anteriormente. Morder el canon, morder los cuerpos y morder los versos para deshacer las normas de género y de sexualidad.

\section{Subversiones vampíricas, caníbales y BDSM del "Cuerpo lesbiano"}

La erotización del vampirismo, tópico literario sáfico heredado del Carmilla ${ }^{13}$ decimonónico y perteneciente a la subcultura lesbiana gracias a la difusión popular promovida por el cine, aparece en múltiples poemas de estas artistas mediante la ocurrencia del término "dientes". Bien se sabe que el vampirismo literario y

\footnotetext{
${ }^{13}$ Novela corta escrita por Sheridan Le Fanu en 1872 (veinticinco años antes que el Drácula de Stoker), inspirada en la leyenda de la condesa Isabel Báthory de Ecsed.
} 
pop fue una manera de representar las uniones carnales secretas fuera de las normas heteropatriarcales y de experimentar otras identidades. Aquí lo que sucede es que estas voces deseantes pasan entonces de los márgenes peligrosos de las representaciones al centro de la página alumbrada, al asumir su monstruosidad contagiante, y al retomar en primera persona el potencial de la figura vampírica de desestabilización de los códigos de género, entre lo "normal" y lo "anormal", lo "humano" y lo "inhumano". La recuperación en voz femenina de estas mordeduras pasionales se traduce por las mordeduras en los versos de Elvira Sastre, que parecen grabar en la piel la memoria de los encuentros eróticos pasados: "mordiscos de otras arraigados en mis hombros [...]/ mis manos arrugadas con tus dientes" (Sastre 2014: 11). Un poema de Cartografía del deseo de Ana Martínez juega con los géneros al cantar una escena de doble penetración digital y dental:

\author{
Esperando el almizcle de tus dedos \\ voy a guardarme todos los orgasmos \\ para ofrecerme intensa al placer de tus caricias. \\ Y cuando estés vampiro clavándote en mis hombros \\ escarcharme con gritos que provoquen \\ el estallido seco de tu reciente herida. (Martínez 2015: 49)
}

El deseo depredador también aparece en estos versos vampíricos de Txus García: "Por los dientes,/ que te codician afilados" (García 2011: 29), tanto como la representación del orgasmo mediante la acción de los dientes: "el monte más crepuscular./ Desgarrarán mis dientes/ suspiros de placer desconocido/ mientras nos llueve fuera" (Martínez 2015: 48). Por otro lado, los reptiles podrían representar otra forma de vampirismo sexual puesto que se manifiestan en recurrentes animalizaciones de Laia López Manrique: "el hallazgo suave/ acerado/ mordiente/ como el deseo de un áspid que respira su veneno" (2012: 114), o de Isabel Serrato: "Tener ganas de ti,/ querer morder tu/ carne como un saurio,/ en los lugares imposibles" (2012: 84).

Por su parte, los versos de María Castrejón nos llevan hacia una reescritura del mito de Eva entre vampirismo y canibalismo lesbianos: "muerdo tu cuello/ acostumbrada como estoy a arrancar con los dientes/ los frutos de los árboles" (Castrejón 2011: 46). A este propósito, Julien Picquart recuerda en su obra Notre désir cannibale que "La scène du fruit défendu, c'est déjà, dès les premières pages de la Bible, le lien établi entre nourriture et sexualité" (Picquart 2011: 21). Del mismo modo, la religión católica les ofrece a estas poetas con su teoría de la transustanciación, otra posibilidad de subversión con la escritura de un canibalismo erótico que se inscribe en el beber la sangre (no eucarística, sino menstrual, y/o provocada por las mordeduras carnales). La ingestión de la sangre de la otra provoca entonces una fusión total simbolizada por la interpenetración de posesivos en estos versos: "una sed imperiosa de sorberse/ mi carne es tu carne/ tu cuerpo es mi cuerpo/ mi sangre es tu sangre" (Peri Rossi 2005: 784), o en el poema de título evocador, "Comunión", de Cristina Peri Rossi, invadido por el campo léxico religioso que describe un encuentro sexual: 


\author{
y como de un cáliz \\ bebí la sangre de tus entrañas \\ la sangre que manaba entre tus piernas [...] \\ Tú escancias desde los orígenes \\ tus óvulos tu menstruo tu celo. \\ Y luego, \\ te di a beber mi propia sangre. (Peri Rossi 2014: 25)
}

Del beso-mordedura, pasamos entonces al beso-ingestión en este movimiento de apertura de labios de una boca que desempeña a la vez un papel de órgano sexual y digestivo. El campo léxico de la acción de comer y del hambre irrumpe en los poemas pornográficos con connotaciones altamente sexuales: "había que devorarse mutuamente" (Peri Rossi 2005: 784), "me ha entrado un apetito voraz" (Peri Rossi 2005: 816), "la enfermita de tu hambre venérea" (García 2011: 73). En el poema pornográfico de Txus García titulado "Ñam, ñam", vienen nombradas las zonas erógenas en relación con el comer: "clítoris hambriento" (García 2011: 58), tanto como en otros poemas donde las partes del cuerpo deseado se someten a la ingestión: "como mucho chocolate [...]/ bombones con forma de concha marina [...]/ bombón o pezón/ labio o ros/ bombón o clítoris/ bombón o lóbulo" (Peri Rossi 2005: 808), "devoraba tus pechos tu pubis tus flancos" (Peri Rossi 2005: 845). El motivo caníbal cumple aquí la misma función que el vampírico al proponer una subversión poética de las sexualidades normadas con la asunción de deseos ob-scenos que alteran lo socialmente aceptado con una radicalidad asumida.

La animalización de la sexualidad se revela en los versos de las poetas que llegan a convertirse en verdaderas bestias caníbales frente al cuerpo femenino al que quieren devorar: "mis lobos interiores/ mis fieras hambrientas" (Peri Rossi 2005: 810), "animalitos en celo/ bramaban mis vísceras hambrientas maternales hienas" (Peri Rossi 2005: 805), "Como las felinas que persiguen a las gacelas/ regresa de la cacería con las fauces ensangrentadas/ y restos de carne entre los dientes./ Ha comido/ ha gozado" (Peri Rossi 2005: 834), "Soy tu carcoma voraz,/ tu animalillo entregado" (García 2011: 73). Nada más explícito que la figura de la "manta religiosa" (Castrejón 2011: 92) que es el título de un poema de María Castrejón, y que aparece lesbianizada en un poema de Txus García: "la bella amazona me devoró tras la cópula" (2011: 13): poseer el cuerpo de la otra hasta el punto de matarla, simbólicamente, en los poemas. Llevar la representación de las sexualidades y las identidades hacia límites poco experimentados.

El canibalismo sexual llega al extremo de devorar el interior de los cuerpos deseados con una carnalidad visceral y exhibicionista generalizada: "nadaba entre tus zumos aterrizaba/ en tus entrañas/ y vísceras cualesquiera" (Peri Rossi 2005: 845), "Sangre viva de vivo deseo [...]/ A dentelladas tristes mi boca/ te muerde a oscuras las entrañas" (Rodríguez Callealta 2012: 137), "Nosotras nos mordíamos la boca para provocar la llaga/ nos abríamos las rodillas y después/ arrancábamos la costra, mostrábamos/ el hueso a las niñas" (Juan 2014: 21). Por cierto, estos últimos versos proceden de un poemario de Carmen Juan de título 
programático, Amar la herida, y abren en efecto las zonas corporales abyectas que la sociedad no quiere ver.

Para proseguir por este camino, cabe señalar que la carnicería parece ser un espacio privilegiado para establecer una relación aún más extrema entre Eros y Tánatos, como es el caso en el poema de María Eloy-García, en el que el yo poético se inventa un imaginario sexual con "La carnicera Muriel":

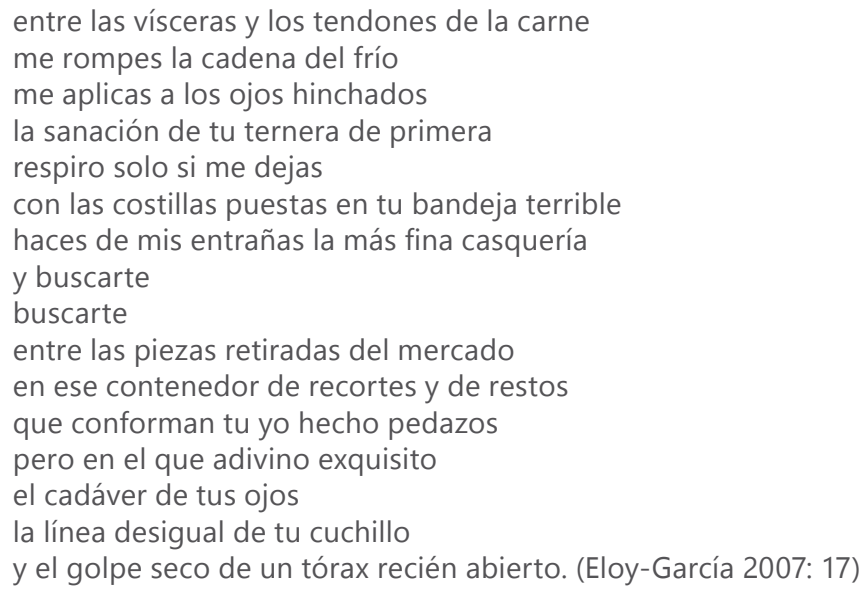

El canibalismo erótico y carnicero se asume también en toda su abyección desestabilizadora en el libro de dibujos Cuervos vienen, carne huelen de Sandra March, acompañados de "versos cárnicos" (March 2012: 20) de la poeta María Castrejón. ${ }^{14}$ En esta obra, el deseo dialoga a la perfección con los retratos de carne y pescado despedazados que solemos ver expuestos en los mercados y las carnicerías. Por ejemplo, en la doble página siguiente, leemos y asistimos a una escena carnal de bondage que lleva a una excitación muy marcada, metaforizada por el destrozo de la carne "picada" y "entrecortada" (March y Castrejón 2012: 84-85):

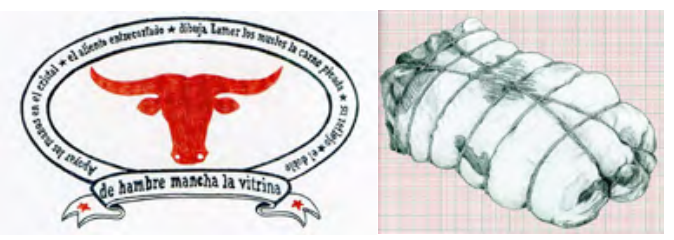

(C2012 March y Castrejón Todos los derechos reservados

\footnotetext{
14 En performances por los pueblos españoles, se repartieron en las carnicerías y en las pescaderías estos versos y sus dibujos impresos en los papeles para envolver la carne y el pescado que compraban los clientes. Por otro lado, cabe precisar que una parte de este libro, impresa sobre unas servilletas, ganó el primer premio en el II Premio de Poesía Experimental Francisco Pino otorgado por la Fundación Jorge Guillén.
} 
En la siguiente, el juego de rol sexual entre una asesina y su víctima deriva hasta la contracción de sus "esfínteres" que la llevará al orgasmo sanguinolento, o en otras palabras y según la expresión consagrada, a la famosa "pequeña muerte" (March y Castrejón 2012: 68-69):

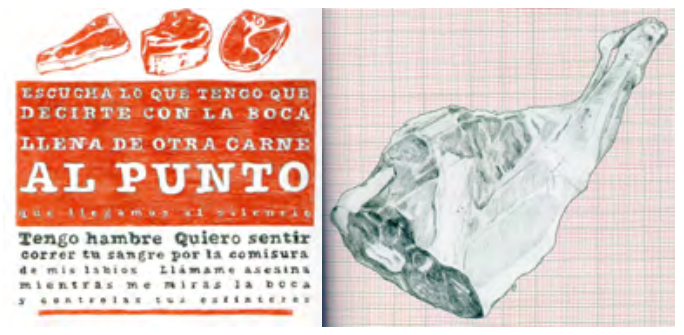

C2012 March y Castrejón Todos los derechos reservados

Lo pornográfico aparece también en estas dos escenas de pescaderíamarisquería (y BDSM) con una nueva pintura en femenino de L'origine du monde de Courbet, con un trozo de salmón y unos versos que recuerdan el fisting (March y Castrejón 2012: 112-113), o un zoom sobre una mano-cangrejo, asesina y erotizada, en medio de la ingestión de la sangre (March y Castrejón 2012: 8889):
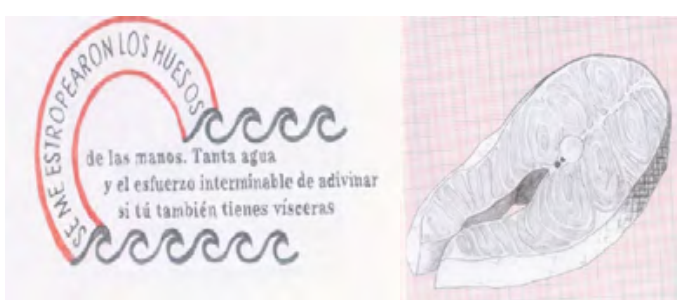

C2012 March y Castrejón Todos los derechos reservados

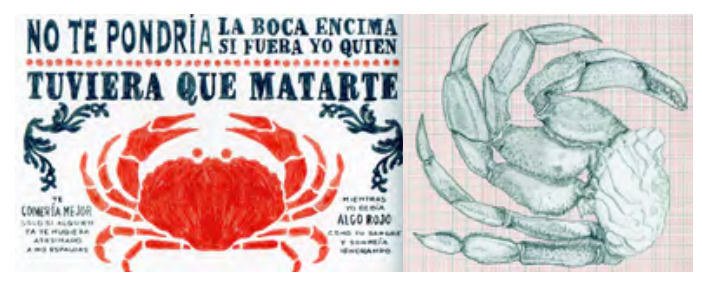

(C)2012 March y Castrejón Todos los derechos reservados

El despedazamiento del cuerpo erótico pasa justamente por el desplazamiento de la mirada deseante hacia otros órganos que los genitales, para producir nuevas prácticas sexuales y textuales que se inscriben dentro de la escritura wittigiana de El cuerpo lesbiano. Las manos, los dientes, los dedos invaden el es- 
pacio de la página poética, como ya se pudo percibir anteriormente, conformando múltiples símbolos fálicos que permiten salir del falocentrismo heteronormado vigente. Pero la poetización de un deseo anatómico nos adentra también en la reapropiación de cuerpos marginados, órgano por órgano, con una precisión casi quirúrgica en el intercambio erótico escrito por Laia López Manrique: "Ella era mi mano, mi apósito bronquial, la estructura del cráneo, el hígado y la orquídea flotante que brotaba algunas noches de mi lengua" (2014: 60), o por Laura A. Cancho: "Sus dedos son largos como brazos/ entran en el cuerpo y arrancan las arterias/ besando suavemente la frente por donde miran/ desde el lugar donde ciegan los pulmones" (2013: 49).

Se trata de reconquistar milímetro a milímetro, y mediante la asunción de estas sexualidades lesbianas invisibilizadas, un cuerpo que se habían otorgado las voces masculinas heterocentradas: "manos rubias me parten/ el alma del trapecio/ por el que caminan/ erectas/ mis cervicales transparentes" (Castrejón 2011: 81), "solo atravesarte/ hasta asesinar tus cálculos/ renales" (Castrejón 2011: 37). Un poema de $\mathrm{M}^{a}$ Ángeles Cabré nos ofrece una enumeración anatómica y carnal que traduce la excitación y el deseo sexual a través de una descripción orgánica, pedazo a pedazo, en una forma de descubrimiento, (re)conocimiento y conexión corporal que subvierte la escritura de la atracción:

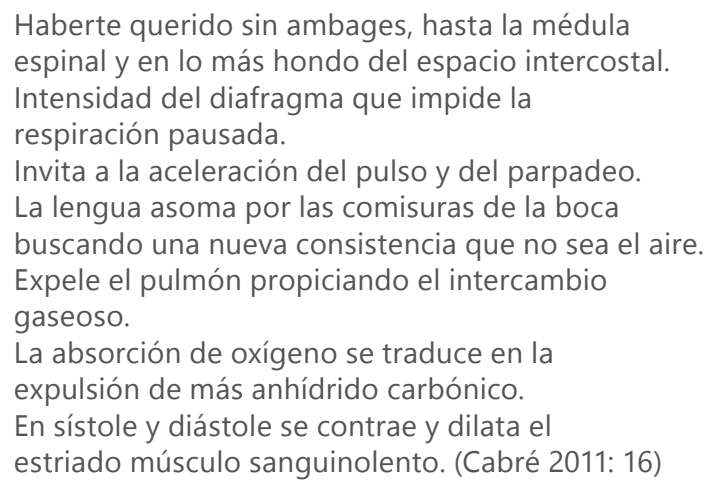

La desterritorialización de lo sexual, característica de las sexualidades BDSM y teorizadas en varios textos de Gayle Rubin y Michel Foucault, entre otras y otros, en oposición al sistema de deseo heteropatriarcal, se expresa de la manera siguiente en la declaración del crítico y sociólogo Javier Sáez al hablar de las sexualidades queer BDSM durante la Maratón Posporno del MACBA de 2003: "se abandona lo genital como lugar esencial o principal de la sexualidad, y esta se ve desplazada a todo el cuerpo como lugar posible de experimentación de placer" (Sáez 2003). De eso se trata cuando las poetas cuentan sus deseos caníbales hacia cuerpos femeninos despedazados. Ya no se trata de la violencia real impuesta sobre los cuerpos de las mujeres, sino que se procura experimentar los poderes corporales, perturbar simbólicamente el orden preestablecido resignificándolo: en efecto, el BDSM es un movimiento (aunque minoritario) propio de la subcultura lesbiana (y gay) que permite invertir y desnaturalizar las relaciones 
de poder de la sociedad heteropatriarcal, con semejantes metáforas y juegos catárticos. Eso recuerda la antropóloga Gayle Rubin al afirmar:

Le sadomasochisme n'est pas une forme de violence: c'est plutôt un type de jeu sexuel ritualisé et contractualisé; ses amateurs déploient d'immenses efforts pour, quand ils le pratiquent, garantir la sécurité et le plaisir des uns et des autres. Les fantasmes SM sont fondés sur des représentations de scènes de contrainte et sur des pratiques sexuelles qui peuvent paraître violentes à des observateurs non avertis. (Rubin 2010: 244)

Las tecnologías de resistencia sexual BDSM se plasman en los poemas con objetos y verbos que explicitan la relación pornográfica que se desarrolla en ellos. Por ejemplo, en el poema en prosa siguiente de Laia López Manrique, la bajada al centro del deseo poetiza la sexodependencia al "látigo" y al ataque corporal con numerosas modalidades de dominación que salen de los habituales retratos patologizantes. En efecto, a partir de lo asumido como "prohibido", se describe la fascinación de la voz poética por estos encuentros gozosos, por estas "pequeñas muertes", que subvierten el motivo literario del descenso al Infierno:

Mi boca se clava en el espacio vacío de átomos sin vello. He descendido el primer piso con los ojos abiertos. La noche me reta a cerrarlos, a escanciar el néctar ácido de los cuerpos que aguardan dispersos en un lienzo antiguo. [...] La escalera. El látigo, los peldaños olvidados. La germinación lunar del labio que va a besar la mugre que lo vio morir. La fiebre, esa fiebre roja desatada en los párpados hediondos de las horas. Lo prohibido. Chocar, hospedarse en otros cuerpos, ahorcar el óvulo, adorarlo. Lamer. La sangre, mi sangre, nuestra sangre. Ese infierno necesario. [...] Ahora sé que el tramo era infinito, caracola de las lenguas macerando las palabras del agravio, manos en fuga al encuentro de las diosas tiernas. Carne, atlas, reverso de piel despiadada mordiéndome, urgiéndome para que no regrese. Abrevadero de la muerte primera, la muerte embelesada, la que marca los caminos que no seguiremos y por los que estaremos dispuestas a volver a morir. (López Manrique 2014: 54)

El látex como textura intrínsecamente relacionada a las sexualidades BDSM se invita en un poema de María Castrejón que retoma, por cierto, múltiples características que ya hemos señalado como la animalización caníbal y vampírica: "Se escurren las serpientes/ disfrazadas de látex/ las lobas aúllan/ escotes mutilados" (Castrejón 2011: 43). Los objetos, tales como las esposas, las cadenas, aparecen mediante diversas comparaciones en este sexting de Antonia López Valera que vuelve a utilizar el motivo de las mordeduras ya aludidas:

Te deseo.

Me siento como si ahora

me tuvieras esposada.

Si me dices eso

se me acelera la respiración. 
Ahora ¿qué?

Necesito que me toques.

No puedo

has sido tú la que me has encadenado

y ahora doy mordiscos al aire. (López Valera 2014: 14)

El hecho de atar el cuerpo de una mujer según el contrato BDSM se manifiesta en estos versos de Txus García, hasta que las mujeres presentes en el poema pierdan la razón: "Te apresaría por los labios,/ te follaría enloquecida,/ colosal, terrible./ Te ataría las muñecas/ al húmedo cabezal" (García 2011: 47), y se conviertan en animal carnívoro/caníbal, u opten por otras prácticas no convencionales, como el ondinismo poetizado por Begoña Callejón: "Tu orina me fecunda, me cuelgas de la lámpara. Sexo confundido ante el vendaval. Jade y mucosas/ Úteros y hollín/ Gritos y oraciones. Clavadas en la cama con cruces azules. Los senos a rayas te convierten en fiera" (2012: 71). La presencia del término "clavar" (que alude otra vez al Cristo), tanto como los verbos de violencia acumulados, ponen de realce los juegos de poder que se representan de manera catártica en estos versos pornográficos de María Castrejón de aliteraciones muy duras: "Soy la niña que/ te empuja / contra la pared/ y se encaja en tus caderas" (2015: 25),

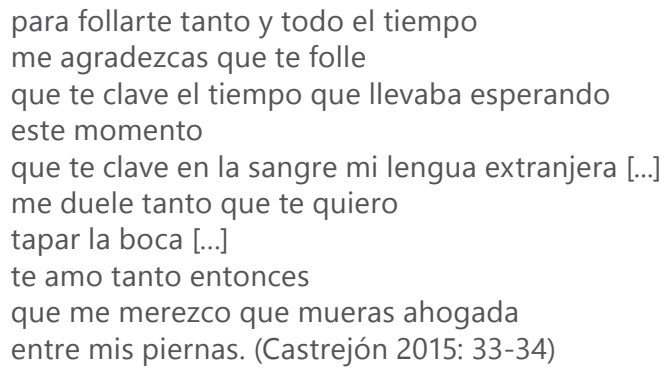

En estas sesiones de sexo BDSM lesbiano y queer, también se representa poéticamente, y sin tapujos, la eyaculación femenina, a la que la ya citada Diana J. Torres da espacio en su libro teórico Coño Potens, o en sus propios versos. Esta eyaculación femenina se desdibuja por ejemplo en los versos de María Castrejón: "Soy la niña que se choca contigo por la calle/ y te clava los huesos de la cadera/ ansiosa de provocar un derrame desconocido" (Castrejón 2015: 23). Poetizar esta manifestación corporal femenina, presentada por la norma hegemónica como tabú, sucia y ridícula, es en sí una rebelión versal en contra del control de esta sociedad heteronormativa, como lo explica Paul B. Preciado: "voici le pharmacoporno-programme de la seconde moitié du xxè siècle: contrôler la sexualité des corps codifiés comme femmes et faire éjaculer les corps codifiés comme hommes" (Preciado 2008: 50). La representación artística de la violencia, diferente de la violencia sistémica real, como bien lo recuerdan Gayle Rubin o 
Eric Fassin ${ }^{15}$ en clave feminista, da un poder subjetivo a cuerpos vulnerados por la sociedad heterosexista, sujetos que encuentran estrategias contractuales para subvertir el orden pornográfico mainstream, sobre todo cuando se espera de los personajes femeninos pudor, dulzura y sentimentalismo. Diana J. Torres se esfuerza en destruir estos estereotipos con una enumeración de verbos en imperativo que termina por una eyaculación femenina, de nuevo amplificada por una connotación alimenticia:

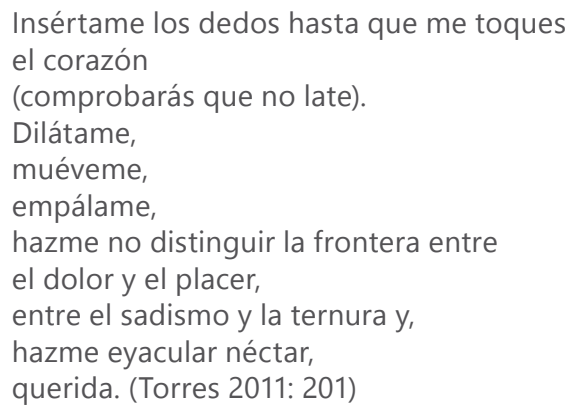

Por consiguiente, la puesta en escena y en poema de situaciones BDSM entre cuerpos femeninos que planifican este juego entre Eros y Tánatos de manera contractual y catártica permite la liberación pornográfica de unos deseos vampíricos y caníbales que asumen su monstruosidad al poetizarla, y provoca el despedazamiento de los cuerpos anteriormente controlados por la norma heteropatriarcal. Esta deconstrucción visceral de las prácticas consensuadas también pasa por el prisma del postporno y de las sexualidades queer que abrieron camino por ejemplo al pornoterrorismo poético de Diana J. Torres.

\section{ESTRATEGIAS POLÍTICAS DE TRANSGRESIÓN POÉTICAS EN LA RADICALIDAD PROSEXO}

En la línea de la difusión del movimiento posporno en los años 90, que se propone promover producciones pornográficas de mejor calidad que la del porno convencional y heterocentrado, y desde una perspectiva feminista prosexo, el filósofo Paul B. Preciado escribe su Manifiesto contra-sexual en el que, entre otras cosas, estudia la tecnología del dildo. Lo que presenta como un artefacto político, permite desestabilizar el falocentrismo al invocar que el dildo precede al sexo masculino. Más allá del consumo capitalista de la pornografía mainstream, las propuestas artísticas postporno y transfeministas en España afirman sus placeres con contundencia e incorrección perturbadoras:

\footnotetext{
15 "... la violence des femmes, telle que le féminisme le revendique, ne pose pas de bombes; elle ne coupe pas de têtes. En revanche, à défaut de prise d'otages, elle s'empare du langage. Ainsi, la guérilla féministe est bien davantage symbolique, comme pour mieux contrer la violence symbolique inscrite dans la domination masculine" (Fassin 2012: 437)
} 
El postporno es de monstruas empoderadas que muestran su sexualidad sin pudores ni tapujos, que muestran sus heridas de guerra, que muestran lo que la sociedad bienpensante les ha invitado a esconder. Muestran cuerpos que rompen con el sistema binario de sexo-género, con las categorías de orientación sexual, de normalidad corporal y de capacidad... y que no solo buscan la excitación sexual, sino que buscan que esta excitación se produzca también a través del humor, la ironía y el discurso crítico. (Preciado 2013: 198)

A pesar de no aparecer citada por Preciado en Testo Yonki entre la larga lista de los géneros que se apropian el terreno prosexo y postporno (Preciado 2008: 297-298), la poesía de algunas poetas a las que ya citamos también se apodera de la cuestión del dildo. Por ejemplo, Txus García nos propone, sin jerarquización ninguna, una lista de varios tipos de órganos fálicos: "con polla/ -de plástico, látex, carne o cristal- y sin ella" (2011: 15), o procede a una metamorfosis radical de su cuerpo deseante en un dildo, que nos recuerda los dibujos corporales que acompañan el Manifiesto contrasexual: "Y cuando nos encontramos/ creo transformarme/ en un dildo gigante,/ vibro compulsivamente/ hasta que gritas, gritas,/ gritas/ o me clavas las uñas" (García 2011: 58). La sexualidad prostética también se puede retratar irónicamente en este poema de María Castrejón: "Mi prótesis/ tu seguro médico platino" (Castrejón 2011: 43), tanto como en su "Niña n..$^{\circ}$ " que pide una felación a otra mujer, mientras ironiza sobre la representación tradicional y estereotipada de las niñas como princesas: "Soy la niña que solo quiere follarte [...]/ y te digo que es bonito que me la chupes despacio/ que te abras de piernas para mí en mi castillo" (Castrejón 2015: 33). En su "Oda al enemigo", Diana J. Torres también reivindica las tecnologías de desnaturalización de las sexualidades con los versos siguientes: "portamos genitales que se montan y desmontan/ y la firme voluntad de defraudar toda expectativa,/ de demoler todo aquello que esperaban que fuéramos" (Torres 2010). La escena postporno también experimenta el sexo ciborg, y la pornografía que emana de los poemas de Diana J. Torres recoge entonces esta propuesta harawayana post-humana y activista en el poema "Metasexual" en el que el yo poético hace el amor con una máquina-niña: "Bombea, bombea, bombea,/ eléctrica niña, reanímame/ que estoy muerta/ paradacardiovascularizada/ de estos orgasmos tan salvajes" (Torres 2011: 201).

Las múltiples sexualidades queer que visibilizan la fluidez entre los géneros se pueden vislumbrar en un poema postidentitario de Mireia Calafell que retoma el pensamiento butleriano y lo integra en estos versos que proponen sexualidades y deseos más potentes, radicales y desestabilizadores de las normas:

Pren la cendra dels teus ulls per recollir els plaers dell lit, ara que saps que hi ha tantes sexualitats com cossos posibles, infinitats de jocs en l'abisme de la nit $i$ en les mentides del carnet d'identitat. Performativitza un cos discursiu, llegeix-te, [...] devora't el sexe, fes-me plorar. [...] 
de saltar tan alt les normes

arribaràs volant on et proposis,

esquerdaràs el mur de la veritat

esfondraràs les lleis de la desídia,

faràs l'amor com mai I'has fet abans. (Calafell 2006: 27)

Se reivindican los cuerpos marginados y rechazados por las normas hegemónicas y binarias en Txus García: "Masculinas, femeninas, intersex, andróginas" (García 2011: 15). Se poetizan y politizan las hormonas como vía de acceso a esta revolución posidentitaria heredada del Testo Yonqui de Preciado: "Hormonadas y sin hormonas" (García 2011: 15), "Mi coño, mi polla, mis orificios todos, mi orgasmo:/ donde he construido un monumento al deseo que siempre/ está lubricado./ Entreno hormonas como si fueran soldaditos" (Torres 2011: 197). María Castrejón opta incluso por una negación total de todas las categorías rígidas de sexos, géneros y sexualidades en su poema programático "anti cuerpos": "No quiero cuerpo/ estigmas de tacones/ ni polla ni coño. [...]/ No quiero dildos/ ni agujeros negros/ ni pescado ni carne"16 (Castrejón 2011: 43-44). Uno de los poemas de Txus García, estudiado por Elena Castro en su Poesía lesbiana queer (Castro 2014: 152-154) "Fucking with 4", lleva el subtítulo de "(polvoqueer I)", y rompe justamente el sistema binario, al imaginar una relación sexual entre dos lesbianas que asumen sucesivamente diferentes papeles que parodian y desestabilizan el control hegemónico de las sexualidades convencionales, al multiplicar las identidades $y$, al mismo tiempo, borrar las fronteras entre ellas:

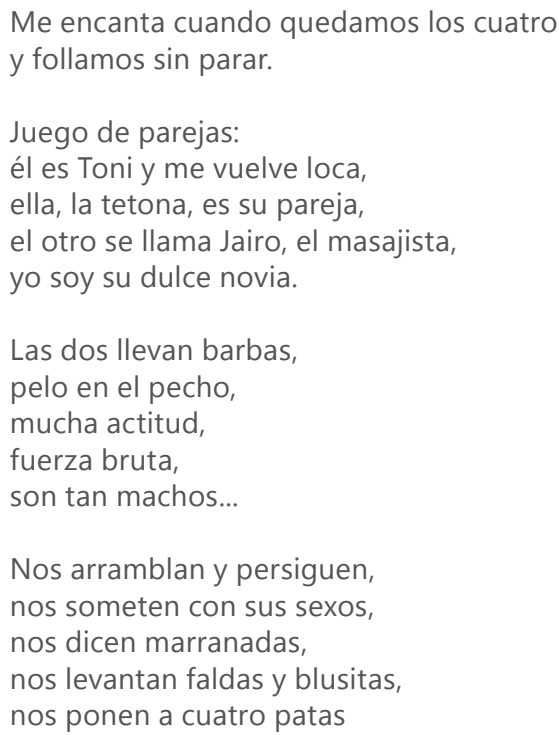

\footnotetext{
${ }^{16}$ Aquí hay un juego de palabras sobre la negación de una posible elección entre todas las sexualidades puesto que en español se utiliza a menudo la expresión "A ti, ¿qué te va? ¿La carne o el pescado?" para saber si una persona es heterosexual u homosexual.
} 


\author{
y finalmente, \\ se dejan sodomizar \\ dulcemente. (García 2011: 67)
}

La representación del ano, también heredada del pensamiento de Preciado, se inscribe en algunos poemas queer, aunque mucho más minoritarios en comparación con todos los elementos señalados anteriormente: aparece en este "polvoqueer" de Txus García, y en Diana J. Torres con "Somos la herejía de todo lo anterior/ convertida en bocas, anos, manos que se follan" (Torres 2010). Al evocar la parte final de las vísceras devoradas, de las que ya hablamos antes, la poeta se apodera de esta zona corporal presentada como lo más abyecto según los códigos de la sociedad heteronormativa, como bien lo analiza Preciado.

Un poema de Txus García, se deja entender como una advertencia amenazadora y sexualizada hacia el sistema opresor "iCuidado!" por parte de estos cuerpos queer en perpetua deconstrucción y resignificación de los insultos, según el famoso proceso teorizado por Butler: "Las locas somos todas y estamos cabreadas,/ las locas te arañamos, te pegamos y escupimos,/ te mostramos nuestros Queer-pos, te tocamos el falito,/ te sobamos las ideas, rompemos tus esquemas" (García 2011: 75). La lucha política desde la agresión que se plasma en estos versos se integraría perfectamente dentro del concepto fraguado por Diana J. Torres en 2001, el "pornoterrorismo", uno de los más transgresores en la actualidad. Sus performances en España, México y Europa, se desarrollan utilizando múltiples medios genéricos, pero aquí, solamente aludiremos a los poemas que ella declama en el escenario (generalmente, después de que alguien del público le saque el poema de la vagina) y que publica al final de su libro Pornoterrorismo o en su blog. Este concepto prolonga a la perfección las reflexiones posporno y queer de las que hablábamos anteriormente, al proponer modalidades de acción concreta, como lo recuerda en su manifiesto esta feminista radical: "el pornoterrorismo, [fue] en parte inspirado por el movimiento queer, en parte por el posporno, en parte por la rabia y la necesidad de expresar ideas inexpresables con los códigos del enemigo" (Torres 2012). Además de aludir al "enemigo" en sus textos teóricos, también lo hace aparecer explícitamente en uno de sus poemas pornográficos titulado: "Oda al enemigo" (Torres 2010). La activista Diana J. Torres expresa lo siguiente a propósito de la creación de su concepto: "¿¿Acaso hay fusión más hermosa que la de las palabras "porno" y "terrorismo"?? La erótica del terror, un terreno sin investigar que se abre como un cadáver listo para la autopsia." (2011: 11): entendemos entonces que la pornografía viene presentada como el mejor medio para derrumbar los códigos vigentes y opresores de esta sociedad heteronormativa. Por consiguiente, el pornoterrorismo radica en la voluntad de atacar mediante formas presentadas como abyectas, tal como lo estudia Karine Bergès: "Formulé autrement, le pornoterrorisme est envisagé comme une revanche contre une société qui blesse, agresse, bâillonne, emprisonne les corps" (2015: 47). Esta reapropiación pornográfica y activista pasa por una guerra simbólica y corporal desde las voces silenciadas, y asumidas como abyectas en sus manifiestos pornoterrorista y transfeminista: "Se trata de 
una nueva máquina de guerra, poderosa y potente: arma eficiente que cuenta con manifiesta potencia de destrucción y creación propia de las bestias" (Torres 2012), "Somos la rabia de la revolución feminista, y queremos enseñar los dientes [...]. Dinamitemos el binomio género y sexo como práctica política" (Torres 2011: 173). Entonces, la rabia es un potente catalizador de toda lucha política, y siempre se relaciona con la pornografía y las sexualidades desenfrenadas como en el poema "Hijxs de puta" de Diana J. Torres: "que os odie no quiere decir que no pueda follaros" (2011: 199), y como en sus deseos de eyaculación destructora de todos los esquemas impuestos por la sociedad: "mi orgasmo apocalíptico se desparrama./ todo es fuego, ceniza, amanecer./ me corro sobre ti, mundo,/ para odiarte mejor" (Torres 2011: 196).

Al interrogar la pornografía dentro del género poético, casi siempre olvidado entre las creaciones propuestas por mujeres en toda su diversidad, hemos podido constatar que un gran número de voces lesbianas y queer se reapropian el espacio poético a partir de los años 2000. Recuperan el poder y la palabra con la elaboración de genealogías mediante la intertextualidad, y devoran lo anteriormente producido por los hombres gracias a la parodia y la incongruencia. Nos ha interesado señalar que las sexualidades marginadas por la sociedad heterosexista se desarrollan libremente en la página poética con la escritura de múltiples escenas pornográficas vampíricas, caníbales y BDSM que permiten la reapropiación de un "cuerpo lesbiano" despedazado, en primera persona, y como sujeto activo de sus deseos desestabilizadores de las normas de género. En cuanto a los cuerpos no convencionales, también hemos constatado que ocupan el terreno de la poesía al escribir versos políticos y eróticos inspirados del posporno y de los movimientos queer, hasta contar con la creación de poemas pornoterroristas por parte de Diana J. Torres.

Estas múltiples propuestas poéticas no pasan desapercibidas entre los círculos que se sitúan fuera de la academia, y tampoco, cada vez más, dentro de esta. El crítico y activista queer Javier Sáez, en su prólogo al poemario Niñas editado por Huerga y Fierro, podría resumir perfectamente lo que hemos querido demostrar en este texto sobre la relación entre pornografía y poesía en el panorama español del siglo xxI:

Los poemas están habitados de niñas poderosas, libres, caníbales, folladoras, viscerales, que no se dejan encerrar en el romanticismo del amor ni en la propia palabra mujer, niñas que roban lo que quieren, niñas sin esencia, pero deseantes y carnales. Son libres porque no tienen miedo ni esperanza, porque desafían a la policía del género [...]. Estas niñas trans, estas niñas "disfrazadas de niñas", estas niñas maricas me fascinan, porque se pasean por los cimientos de nuestras certezas y las cuestionan. (Sáez 2015: 9-10) 


\section{OBRAS CITADAS}

Bel, Sílvia (2010): L'esbòs. Sabadell, Edicions 7dquatre.

Bergès, Karine (2015): "Sexualités dissidentes et performance transféministe: le 'pornoterrorisme' de Diana J. Torres". En Isabelle Prat y Jacques Terrasa (eds.): Image et création au féminin. París, Editions hispaniques, pp. 37-56.

Cabré, Ma Ángeles (2011): Gran amor. Madrid, Egales.

Calafell, Mireia (2006): Poètiques del cos. Cabrera de Mar, Galerada.

Callejón, Begoña (2012): "Begoña Callejón". En Carmen Moreno (ed.): Mujeres que aman a mujeres. Madrid, Vitruvio, pp. 69-80.

Cancho, Laura A., (2013): El silencio de la perla. Madrid, Amagord.

Caro Romero, Joaquín (1973): Antología de la poesía erótica española de nuestro tiempo. París, Ruedo Ibérico.

Castrejón, María (2011): Volveré mucho más tarde de las doce. Madrid, Egales.

- (2015): Niñas. Madrid, Huerga y Fierro.

Castro, Elena (2014): Poesía lesbiana queer. Cuerpos y sujetos inadecuados. Barcelona, Icaria.

Desclot, Miquel (2011): El jardí de les malícies: de la poesia eròtica universal. Barcelona, Angle.

Despentes, Virginie (2006): King Kong Théorie. París, Grasset, Le Livre de Poche.

Eloy-García, María (2007): Cuánto dura cuanto. Almería, El Gaviero.

Fassin, Eric (2012): "Introduction. Représenter la violence des femmes: performance et fantasme". En Coline Cardi y Geneviève Pruvost (eds.): Penser la violence des femmes. París, La Découverte, pp. 433-441.

García, Txus (2011): Poesía para niñas bien, Tits is my bowl. Sevilla, Cangrejo Pistolero Ediciones.

_ (2012). "Txus García". En Carmen Moreno (ed.): Mujeres que aman a mujeres. Madrid, Vitruvio, pp. 51-68.

Juan, Carmen (2014): Amar la herida. Córdoba, La Bella Varsovia.

López Manrique, Laia (2012). "Laia López Manrique". En Carmen Moreno (ed.): Mujeres que aman a mujeres. Madrid, Vitruvio, pp. 107-120.

— (2014): La mujer cíclica. Barcelona, La Garúa.

López Valera, Antonia (2014): Remolinos en septiembre. Barcelona, Carena.

March, Sandra, y Castrejón, María (2012): Cuervos vienen, carne huelen. Barcelona, Autoedición.

Martínez, Ana (2015): Cartografía del deseo. Autoedición.

Moreno, Carmen (ed.) (2012): Mujeres que aman a mujeres. Madrid, Vitruvio.

Paveau, Marie-Anne (2014): Le discours pornographique. París, La Musardine.

Peri Rossi, Cristina (2005): Poesía reunida. Barcelona, Lumen.

- (2009): Playstation. Madrid, Visor Libros.

- (2014): La noche y su artificio. Palencia, Cálamo.

Picquart, Julien (2011): Notre désir cannibale: du mythe aux faits divers. París, La Musardine.

Post-Op (2013): "De placeres y monstruos: interrogantes en torno al postporno". En Miriam Solá y Elena Urko (eds.): Transfeminismos. Epistemes, fricciones y flujos. Tafalla, Txalaparta, pp. 193-210. 
Preciado, Paul B. (2000): Manifeste contra-sexuel. París, Balland.

- (2008): Testo Junkie. París, Grasset et Fasquelle, J'ai Lu.

Rich, Adrienne (1996): "Heterosexualidad obligatoria y existencia lesbiana" [1980], Duoda

Revista d'Estudis Feministes, n. ${ }^{\circ} 11$, trad. de María-Milagros Rivera Garretas, pp. 13-37.

Rodríguez Callealta, Ana (2012): "Ana Rodríguez Callealta". En: Carmen Moreno (ed.): Mujeres que aman a mujeres. Madrid, Vitruvio, pp. 133-144.

Rowbotham, Sheila (1977): Mundo de hombre, conciencia de mujer. Madrid, Debate.

Rubin, Gayle (2010): Surveiller et jouir. Anthropologie politique du sexe. París, Epel.

Sáez, Javier (2003): "El macho vulnerable: pornografía y sadomasoquismo", <http://paroledequeer.blogspot.fr/2015/03/el-macho-vulnerablepornografia-y.html> [última consulta: 7.2.2017].

— (2015): "Prólogo". En María Castrejón: Niñas. Madrid, Huerga y Fierro, pp. 9-10.

Salceda, Pura (2010): Erato bajo la piel del deseo: antología de poesía erótica. Madrid, SIAL. Sastre, Elvira (2014): Baluarte. Granada, Valparaíso Ediciones.

Serrato, Isabel (2012): Nunca fui una princesa de Disney. Sevilla, Benilde.

Tapia, Ana (2012). "Ana Tapia". En Carmen Moreno (ed.): Mujeres que aman a mujeres. Madrid, Ediciones Vitruvio, pp. 37-50.

Torres, Diana J. (2009): Pornopoemas, <https://pornoterrorismo.com/lee/pornopoemas/> [última consulta: 7.2.2017].

— (2010): Poemas, <https://pornoterrorismo.com/lee/poemas/> [última consulta: 7.2.2017].

- (2011): Pornoterrorismo. Tafalla, Txalaparta.

— (2012): Manifiesto pornoterrorista, <https://pornoterrorismo.com/lee/manifiesto-pornoterrorista/> [última consulta: 7.2.2017].

- (2015): Coño Potens. Tafalla, Txalaparta. 